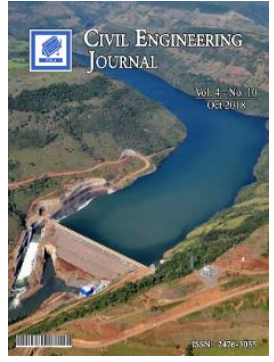

\title{
Effect of Soil and Structure Nonlinear Interaction on the Efficiency of Tuned Mass Damper
}

\author{
Hamid Masaeli ${ }^{a *}$, Mehdi Panahi ${ }^{\mathrm{b}}$ \\ ${ }^{a}$ Assistant professor of civil-structural engineering, University of Ayatollah Ozma Borujerdi, Borujerd, Iran. \\ ${ }^{b}$ Master of structural engineering, University College of Omran-Tosseeh, Hamedan, Iran.
}

Received 27 February 2018; Accepted 21 September 2018

\begin{abstract}
In this paper, three 10,15, and 20-story two-dimensional concrete structures have been used with a moment frame bearing system as models under analysis. First, using various time history analyses by the OpenSees software, the optimal parameters of the tuned mass damper (TMD), including frequency and mass, were obtained. Structures controlled with and without TMD were modelled on three soft, moderate, and hard soil types classified according to Code 2800 . The models were analyzed in terms of time history by 7 ground motions. In order to take into account the nonlinear interaction of soil and structure, the model of the beam on nonlinear Winkler foundation has been used. The results show that nonlinear interaction in most cases reduces the efficiency of TMD. Moreover, as the soil becomes softer, the efficiency reduction of the mass damper increases.
\end{abstract}

Keywords: Tuned Mass Damper; Soil and Structure Nonlinear Interaction; Winkler Model; Time History Analysis.

\section{Introduction}

The soil and structure interaction has a significant effect on the efficiency of passive control systems, especially the tuned mass damper (TMD), which is highly sensitive to the frequency considered for it regarding the frequency of mode or modes of the structure. Due to the fact that, the soil and structure interaction is non-linear in reality, in this paper the changes in the TMD efficiency have been studied by taking into account structures with and without TMD on different soils [1-3].

These control systems are known as tuned mass dampers or TMDs. The initial ideas and general concept for controlling vibration by mass were first introduced in 1909 by Frahm [4]. The basis of the behavior of the balanced mass dampers on the structures is rooted in the performance of dynamic vibration absorbers studied by Frahm. His objective was to reduce the rotational motion of the ship around its longitudinal axis, and, after its development, called it dynamic vibration absorber. Years after the idea of Frahm, Ormondroyd and Den Hartog proposed the first theory which was fully including the damping tool [5]. In the book Mechanical Vibrations by Den Hartog, calculation of the optimal parameters of a tuned mass damper system has been presented. Ormondroyd and Den Hartog developed a more complete model of the idea of shock absorbers [6]. In his book, Den Hartog presented the theory of shock absorbers in the case where the main structure was without damping [7]. Chaojin and Spyrako conducted a research on the seismic analysis of towers and their uplift. In this study, factors like soil hardness, ratio of tower height to foundation width, and the rate of foundation uplift from soil were considered. Furthermore, they investigated the effects of soil hardness on the seismic response of short towers compared to long ones. Their research showed that in an unusual foundation uplift, the seismic

* Corresponding author: masaeli@abru.ac.ir

dol http://dx.doi.org/10.28991/cej-03091174

$>$ This is an open access article under the CC-BY license (https://creativecommons.org/licenses/by/4.0/).

(C) Authors retain all copyrights. 
response turns into the moment and rotation in the hard soils and the high-rise towers and major of the seismic response to the shear in the hard soils and short structures. An important point in their research was the importance of soil hardness on the seismic response of tall and short towers [8]. Gazetas and Apostolou conducted a research on nonlinear soil and structure interaction. In their study, they considered soil behavior as elastoplastic Mohr-Coulomb model, and investigated the behavior of surface foundations exposed to earthquake shocks. They concluded that the steady movement of the uplift in relatively high structures involves effects like P-delta phenomenon and soil yield [9]. Zhou et al., introduced a quasi-dynamic model for analyzing the nonlinear soil and structure interaction. This new model was able to calculate structural responses based on nonlinear behavior between the structure and ground in strong earthquakes. In their research, they showed that structural responses would decrease if the soil and structure interaction was in the nonlinear range and uplift occurred [10]. Fu Wang and Chang Lin, carried out a study on the performance of TMDs, by examining a three-dimensional structure of two degrees of freedom using 1, 3 and 7 mass dampers, taking into account the effect of soil and structure interaction, as well as the presence of torsion due to the asymmetry of the structure. In their research, the effect of resonance control was determined by mass dampers [11].

\section{Tuned Mass Damper (TMD)}

The equation of motion of a system of $\mathrm{N}$ degree of freedom is given as Equation 1 [2]:

$$
M \ddot{u}(t)+C \dot{u}(t)+K u(t)=-M I \ddot{u}_{g}(t)
$$

Where, $\mathrm{M}$ is the mass matrix, $C$ is the damping matrix, and $K$ is the structure stiffness matrix. Given the number of degrees of freedom of the structure, each of the matrices is $n \times n . \mathrm{u}(\mathrm{t})$ is the vector of displacement of dimension $n$, $\ddot{\mathrm{u}}_{\mathrm{g}}(\mathrm{t})$ is the ground motion acceleration due to the earthquake, and $\mathrm{I}$ is the unit vector of $n \times 1$. With the addition of the damper to the structure, the degrees of structural freedom are changed to $n+1$, and the mass, damping and the mass damper stiffness are assembled with the mass matrix, damping, and initial structural stiffness, respectively, hence, the mass, stiffness, and damping matrices of the system are expressed as Equations 2, 3 and 4.

$$
\begin{aligned}
\mathrm{M} & =\left[\begin{array}{ccccc}
\mathrm{M}_{1} & 0 & 0 & 0 & 0 \\
0 & \mathrm{M}_{2} & 0 & 0 & 0 \\
0 & 0 & \ddots & 0 & 0 \\
0 & 0 & 0 & \mathrm{M}_{\mathrm{n}} & 0 \\
0 & 0 & 0 & 0 & \mathrm{M}_{\mathrm{TMD}}
\end{array}\right] \\
\mathrm{K} & =\left[\begin{array}{ccccc}
\mathrm{k}_{1} & -\mathrm{k}_{1} & \cdots & 0 & 0 \\
-\mathrm{k}_{1} & \mathrm{k}_{1}+\mathrm{k}_{2} & \cdots & 0 & 0 \\
\vdots & \vdots & \vdots & 0 & 0 \\
0 & 0 & 0 & \mathrm{k}_{\mathrm{n}}+\mathrm{k}_{\mathrm{TMD}}-\mathrm{k}_{\mathrm{TMD}} \\
0 & 0 & 0 & -\mathrm{k}_{\mathrm{TMD}} & \mathrm{k}_{\mathrm{TMD}}
\end{array}\right] \\
\mathrm{C} & =\left[\begin{array}{ccccc}
\mathrm{c}_{1} & -\mathrm{c}_{1} & \cdots & 0 & 0 \\
-\mathrm{c}_{1} & \mathrm{c}_{1}+\mathrm{c}_{2} & \cdots & 0 & 0 \\
\vdots & \vdots & \vdots & 0 & 0 \\
0 & 0 & 0 & \mathrm{c}_{\mathrm{n}}+\mathrm{c}_{\mathrm{TMD}} & -\mathrm{c}_{\mathrm{TMD}} \\
0 & 0 & 0 & -\mathrm{c}_{\mathrm{TMD}} & \mathrm{c}_{\mathrm{TMD}}
\end{array}\right]
\end{aligned}
$$

\section{Models, Soils, and Foundations Analyzed}

In order to carry out the analyses in the present thesis, three 10, 15, and 20-story concrete structures have been used with a moment frame bearing system with moderate ductility. The structures were first designed in the SAP2000 software, based on the Sixth National Building Regulations, 2800 Code, $4^{\text {th }}$ Revision, and ACI 318-08. The frames were extracted from a regular plan in a two-dimensional state according to figure (1). The building use was residential, and the dead and live loads of floors and the roof were $650 \mathrm{~kg} / \mathrm{m}^{2}$, equivalent to 6374.32 and $200 \mathrm{~kg} / \mathrm{m}^{2}$, equivalent to 1961 . $33 \mathrm{~N} . \mathrm{m} / \mathrm{m}^{2}$, respectively. In this paper, 3 soil types II, III, and IV in the 2800 code were used to take into account the soil and structure nonlinear interaction [12]. The foundations were shallow type and considered to be perpendicular to the strip plate, and only the foundation of the 20-story frame was of raft foundation on the soil type IV. In order to obtain the dimensions of the foundations, first, the load bearing capacity of all three soil types was obtained using the Terzaghi method, then the dimensions were determined. The height of the foundations was also obtained based on the shear control (one-way and two-way). 

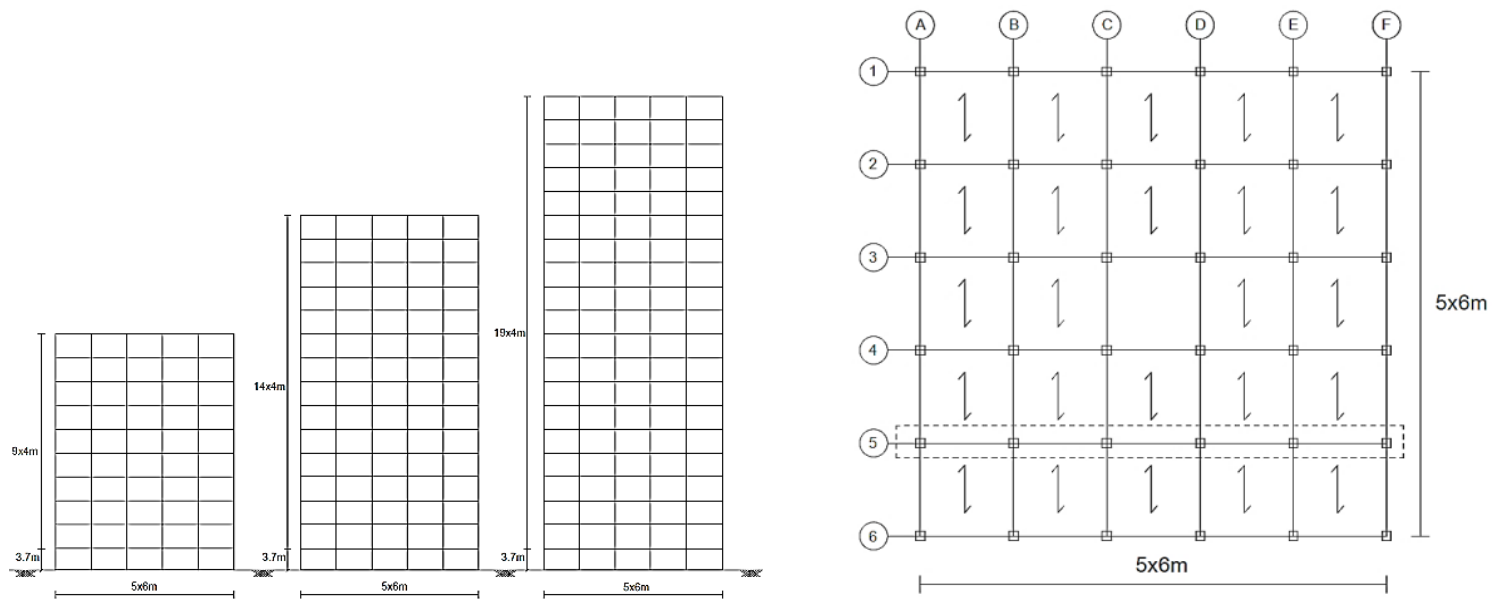

Figure 1. 2-dimensional, 10, 15, and 20-syory frames extracted from the plan, for conducting analyses

\section{Ground Motion Records}

A set of 7 ground motions were used in order to perform dynamic analysis in the present study. The ground motions were firstly scaled according to the 2800 Code and then used. The characteristics of ground motions are presented in Table 1.

The full characteristics of ground motions were described in FEMA p695 according to reference [16].

Table 1. Characteristics of ground motions

\begin{tabular}{ccccccc}
\hline Name & Year & Station & Mw & PGA $(\mathbf{g})$ & PGV $(\mathbf{c m} / \mathbf{s})$ & PGD $(\mathbf{c m})$ \\
\hline Erzincan & 1992 & Erzincan & 6.7 & 0.49 & 96 & 21.9 \\
Imperial Valley & 1979 & El Centro Array & 6.5 & 0.44 & 112 & 27.6 \\
Irpinia & 1980 & Sturno & 6.5 & 0.31 & 45 & 32 \\
Nahanni & 1985 & Site 1 & 6.8 & 1.18 & 44 & 14.5 \\
Hector Mine & 1999 & Hector & 7.1 & 0.34 & 42 & 22.5 \\
Kobe & 1995 & Nishi-Akashi & 6.9 & 0.51 & 37 & 9.5 \\
Manjil & 1990 & Abbar & 7.4 & 0.51 & 54 & 14.9 \\
\hline
\end{tabular}

\section{Winkler Model}

The method and model used to consider the soil and structure nonlinear interaction was the beam on nonlinear Winkler foundation model. Based on the relations of the codes, Hardin et al. presented the stiffness and damping parameters of the foundation as a beam on nonlinear Winkler foundation model $[3,14,15]$. In this model, extensive elements of spring and damper were used to simulate the soil behavior.

The Winkler model includes the flexible beam elastically meshed element for modeling the foundation behavior and Winkler linear and nonlinear elements for modeling soil behavior. In this model, the vertical springs are extensively distributed proportional to the surface share of each of the nodes and the horizontal spring is applied centrally to one of the end nodes. Figure 2 demonstrates the model of the interaction of the structure and soil and the foundation [3, 13].

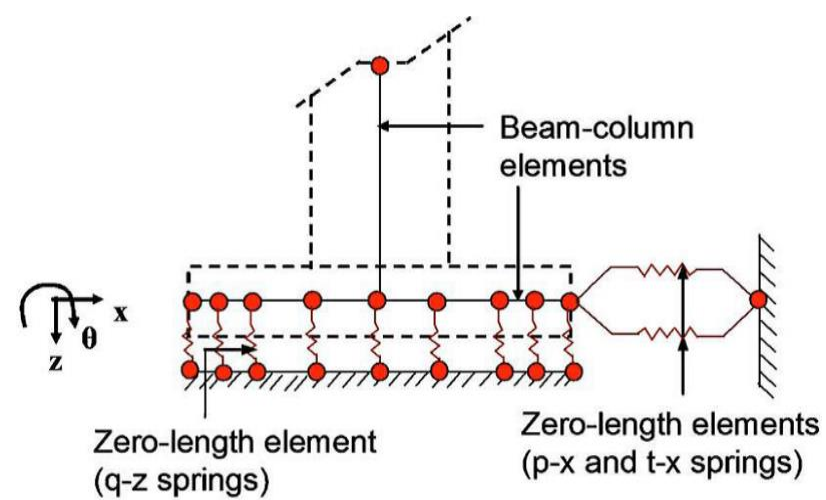

Figure 2. Schematic of the beam on nonlinear Winkler foundation model [13] 
In Figure 3a and 3b, a schematic of the models of this study can be observed.

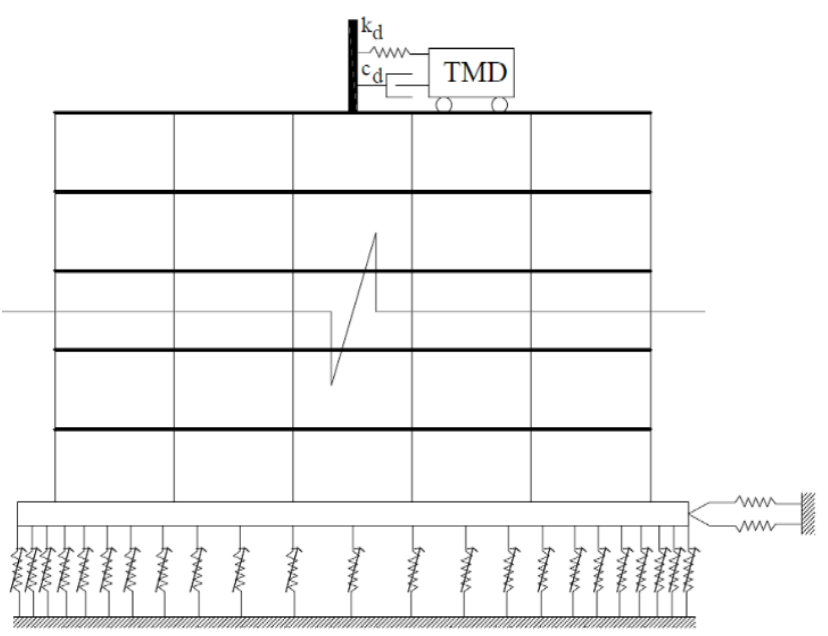

(a)

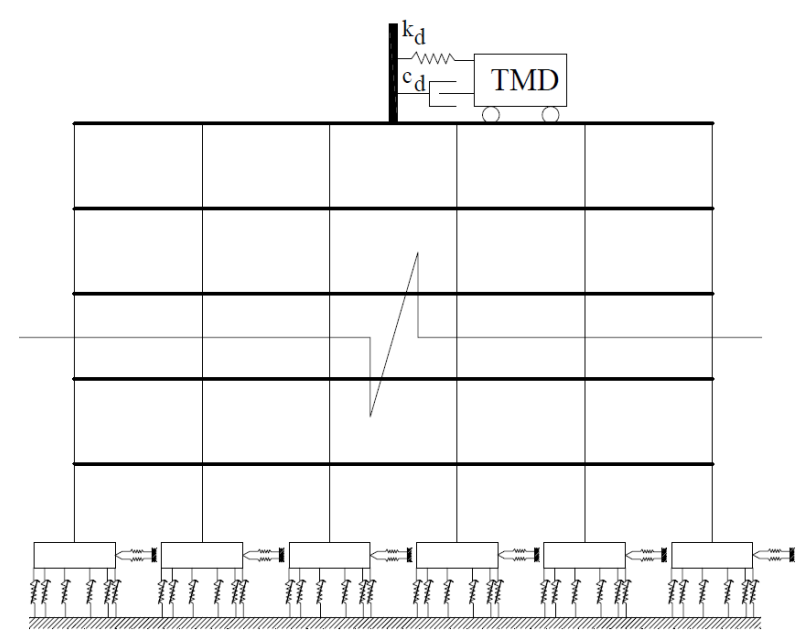

(b)

Figure 3. Schematic of the soil and structure system equipped with a tuned mass damper, a) with a strip foundation in the direction perpendicular to the plane, $b$ ) raft foundation

\section{Analysis}

The TMD performance criterion was considered according to Equation 5 to find its optimal parameters.

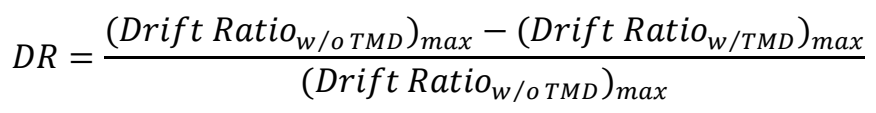

In all three frames, the mass dampers were tuned with the first vibration mode. Since the first mode produces the largest displacement in the structure's roof, the mass dampers were placed on the roof in all three frames. After numerous time history analyses for each of the frames introduced, under the record category, their effective parameters were obtained for each frame and stated in table 2. The analyses showed that increasing the mass of the damper causes a greater reduction in the response and an increase in the efficiency of the damper, however due to the practical limitations, the increase of mass more than $5 \%$ of the total mass of the structure does not seem reasonable. Thus, the damper mass was determined to be $5 \%$ of the total mass of the frame in all three structures. It was also found that increasing the damping ratio of the mass damper has little effect on its efficiency. Damping of the mass damper was obtained based on the Riley damping.

Table 2. Mass ratio and optimal frequency ratio for frames

\begin{tabular}{rcc}
\hline Structure & $\boldsymbol{m}_{T M D} / \boldsymbol{m}_{\boldsymbol{s}}$ & $\boldsymbol{\omega}_{\text {TMD }} / \boldsymbol{\omega}_{\mathbf{1}}$ \\
\hline 10-Story & 0.05 & 1.05 \\
15-Story & 0.05 & 0.8 \\
20-Story & 0.05 & 0.7 \\
\hline
\end{tabular}

After finding the optimal parameters of TMD, frames with and without TMD, in states with and without nonlinear interaction located on all three types of soil, have been analyzed in terms of time history under the above mentioned records, in which the percentage efficiency of mass damper according to the performance criterion defined in Equation 5 for each ground motion is as follows.

- 10-story frame: In earthquakes, Erzikan 8.38\%, Nahanni 25.63\%, Imperial Valley 9.03\%, Irpinia 12\%, Kobe $17.43 \%$, Manjil 14.12\%, Hector\% 23.76\%.

- $\quad$ 15-story frame: In earthquakes, Erzikan 22.13\%, Nahanni 12.03\%, Imperial Valley 29.94\%, Irpinia 14.06\%, Kobe $19.63 \%$, Manjil $17.94 \%$, Hector\% $14.21 \%$.

- 20-story frame: In earthquakes, Erzikan 9.35\%, Nahanni 14.74\%, Imperial Valley 41.39\%, Irpinia 23.39\%, Kobe $22.87 \%$, Manjil 26.35\%, Hector\% 4.71\%. 
Analyses have been continued considering the nonlinear interaction. As an example, the outputs presented relate to the drift ratio of the stories and the absolute acceleration for the Imperial Valley and Kobe earthquakes, in addition, the outputs for the base shear are associated with each of the 7 ground motions. The change in the TMD efficiency can be compared by the graphs presented.

Graphs in Figures 4 to 9, Figures 10 to 15, and Figures 16 to 18 demonstrate the drift ratio of stories, the absolute acceleration of the stories for Imperial Valley and Kobe earthquakes, and the maximum base shear for all ground motions, respectively. Graphs have been presented for all three structures with and without TMD in states with and without nonlinear interaction under the influence of all three soil types mentioned. In the graphs relating to the base shear, the horizontal axis represents the ground motion number in the following order:

1) Erzikan, 2) Hector, 3) Imperial Valley, 4) Irpinia, 5) Kobe, 6) Manjil, 7) Nahanni

- w/o TMD-Fix - w/ TMD-Fix

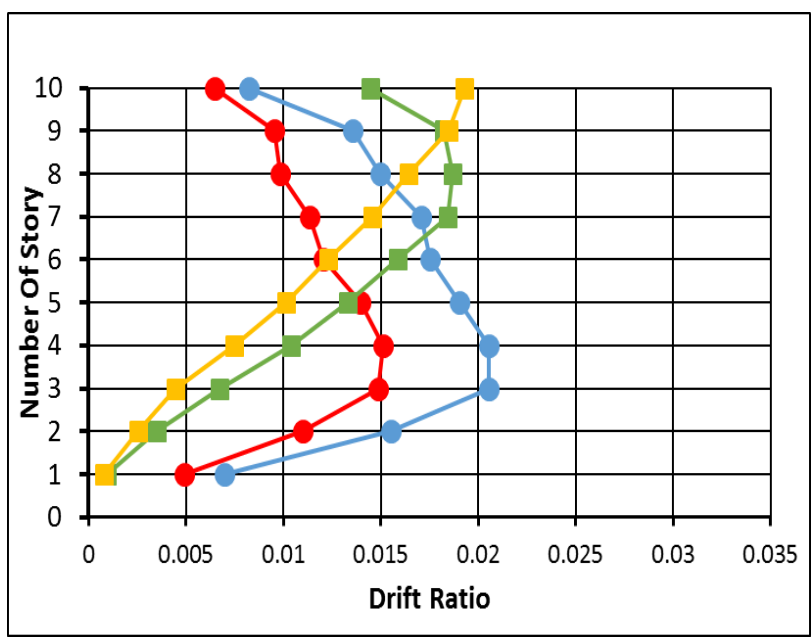

Soil Type II w/o TMD-NLSSI - w/ TMD-NLSSI

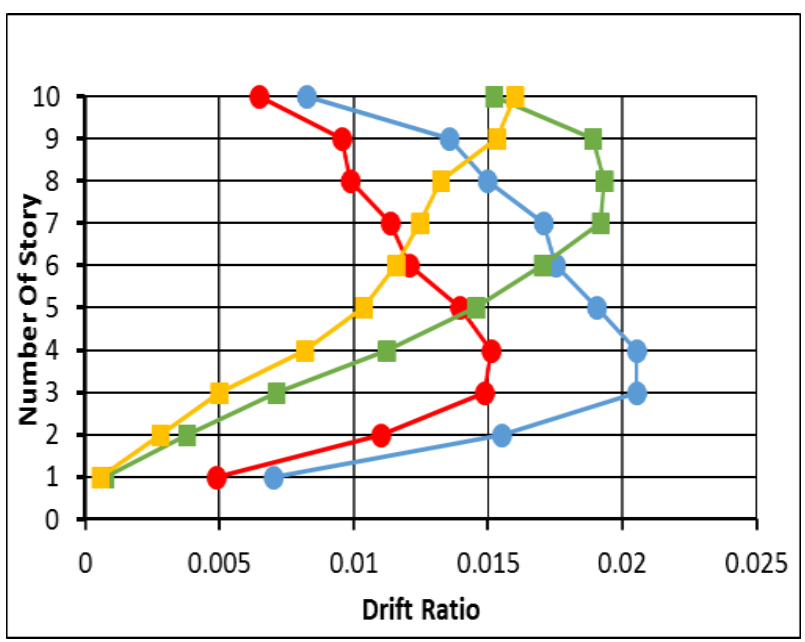

Soil Type III

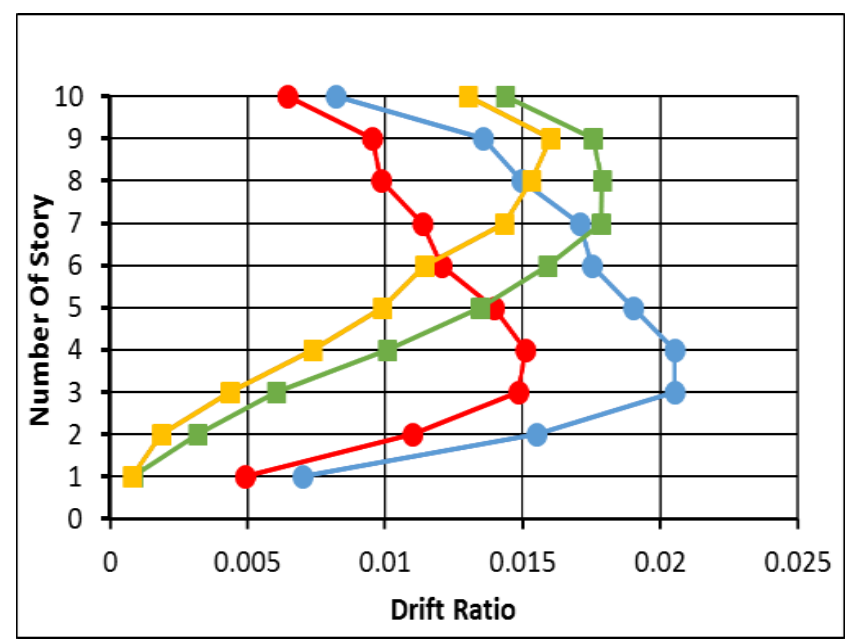

Soil Type IV

Figure 4. Drift ratio of stories of the 10-story frame on soils type II, III, and IV under the Imperial Valley ground motion 


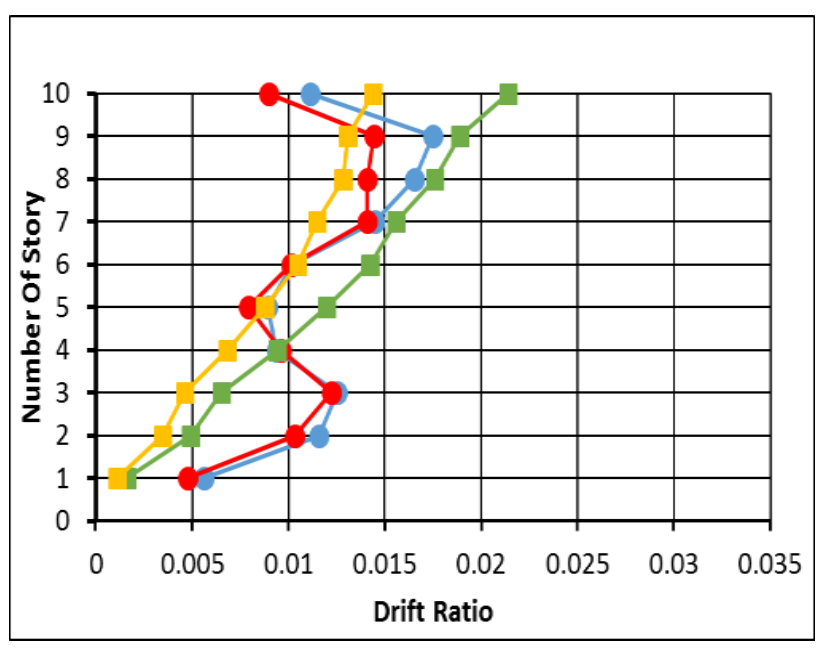

Soil Type II

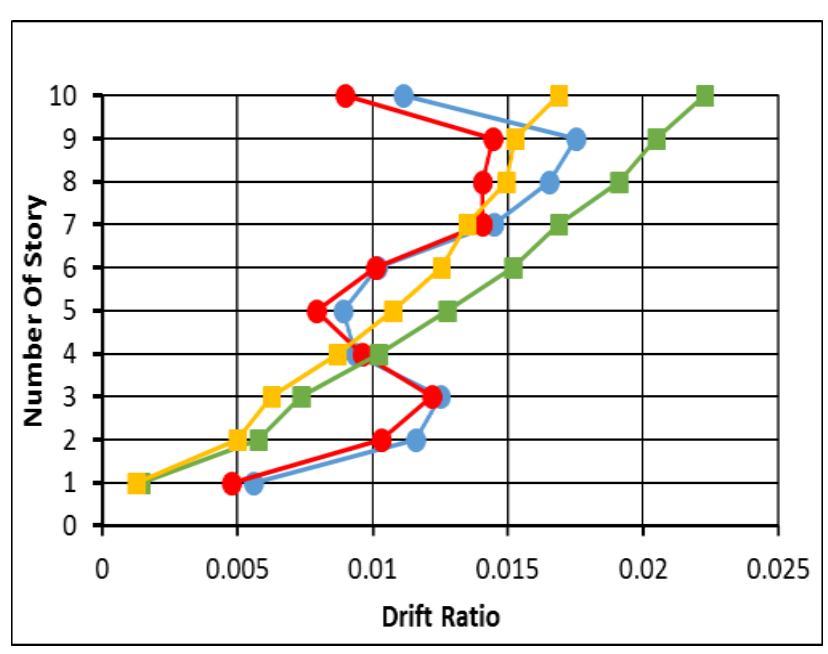

Soil Type III

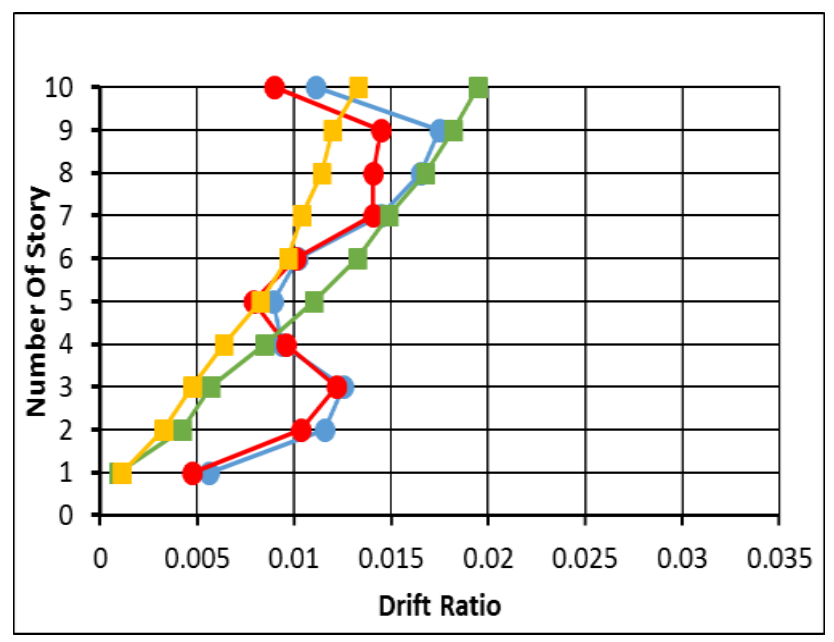

Soil Type IV

Figure 5. Drift ratio of stories of the 10-story frame on soils type II, III, and IV under the Kobe ground motion

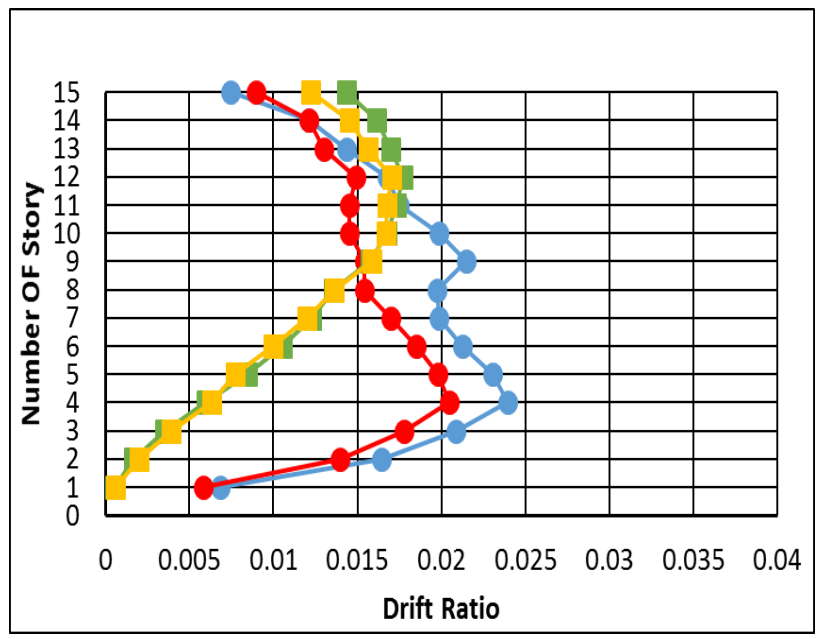

Soil Type II

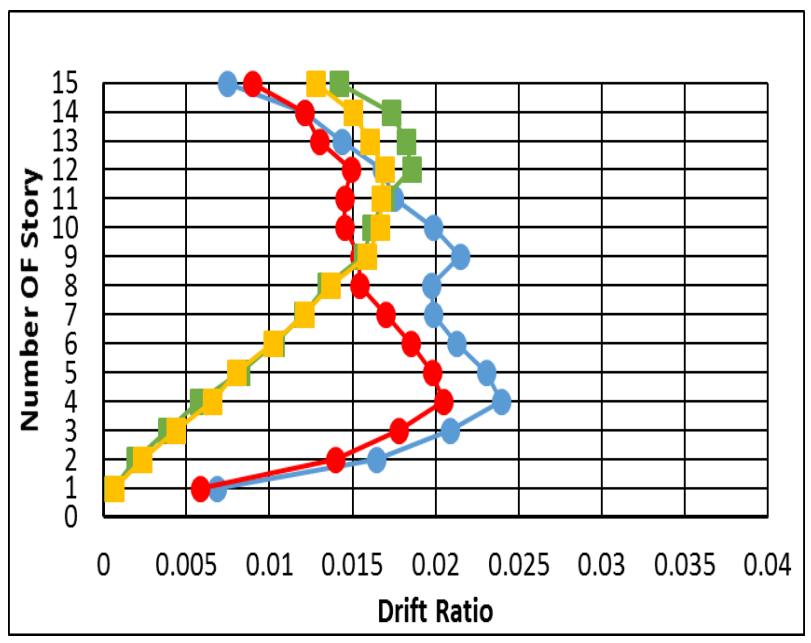

Soil Type III 


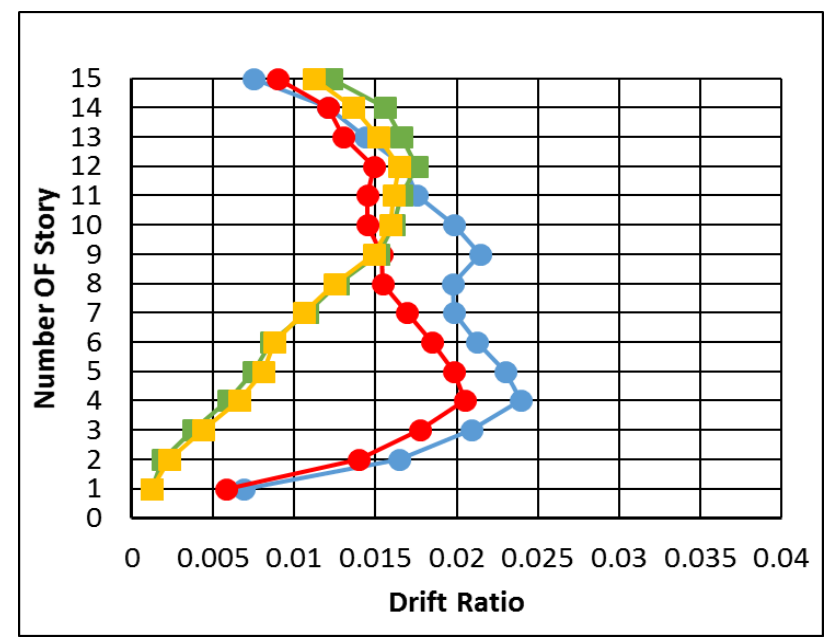

Soil Type IV

Figure 6. Drift ratio of stories of the 15-story frame on soils type II, III, and IV under the Imperial Valley ground motion

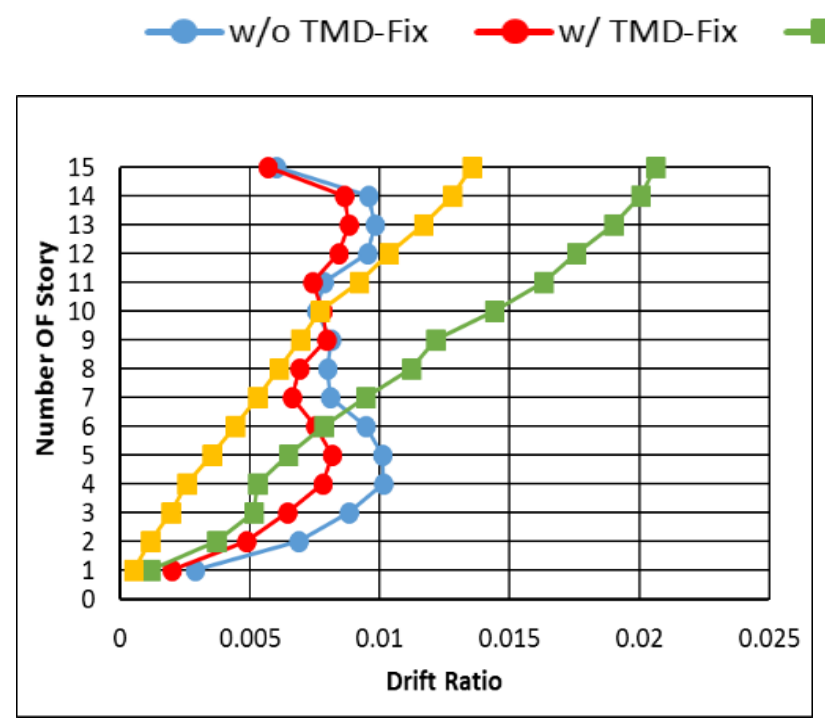

Soil Type II w/o TMD-NLSSI

-w/ TMD-NLSSI

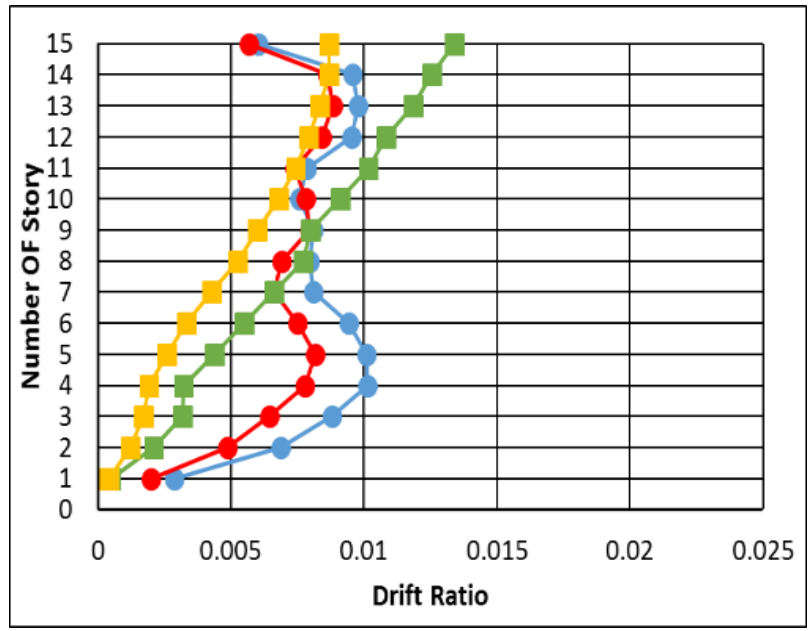

Soil Type III

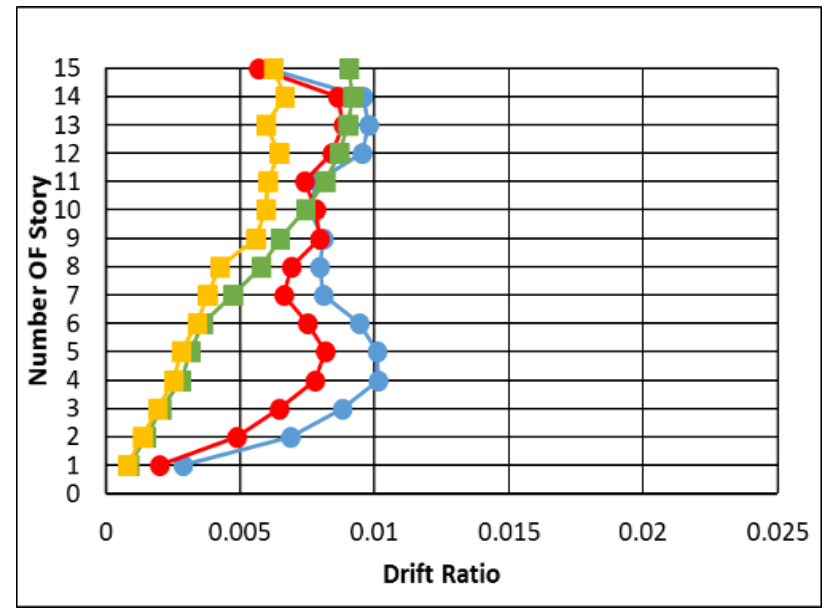

Soil Type IV

Figure 7. Drift ratio of stories of the 15-story frame on soils type II, III, and IV under the Kobe ground motion 
- w/o TMD-Fix - w/ TMD-Fix $\quad-$ w/o TMD-NLSSI - w/ TMD-NLSSI

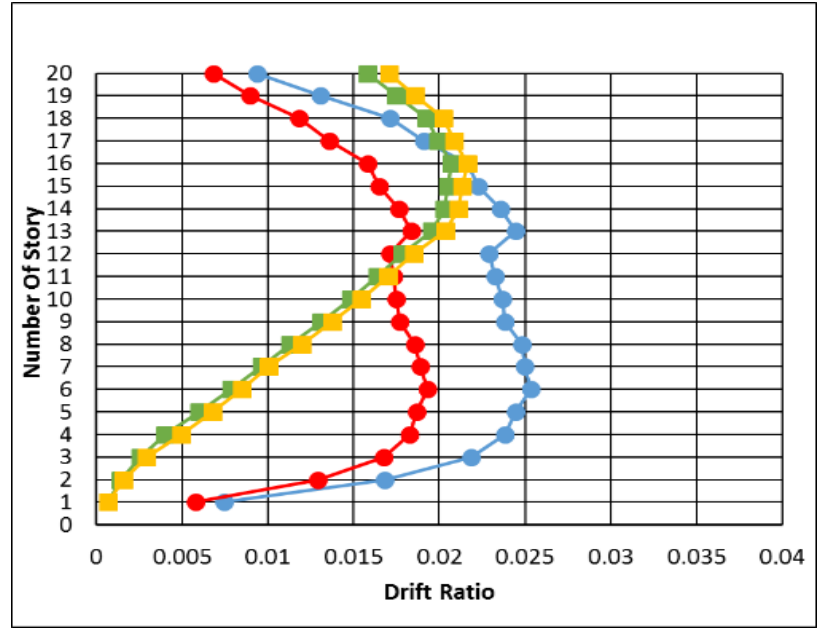

Soil Type II

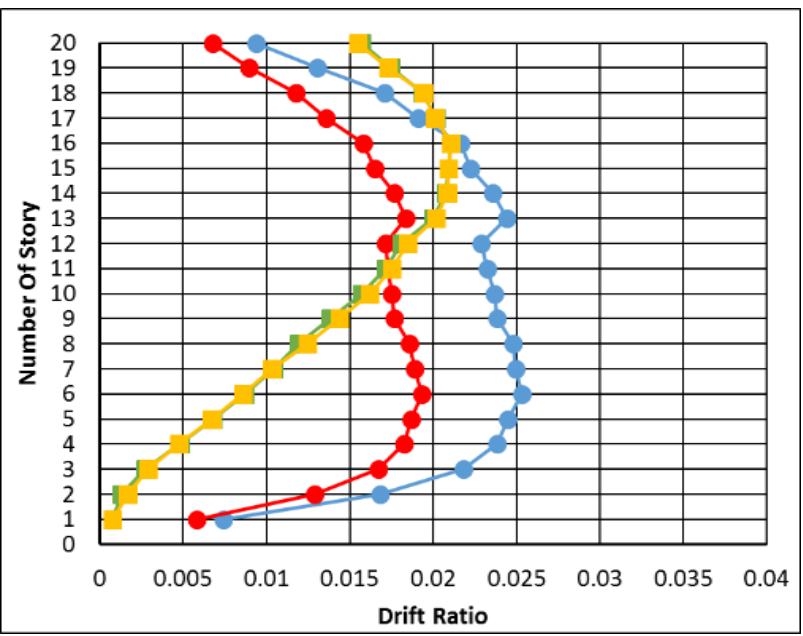

Soil Type III

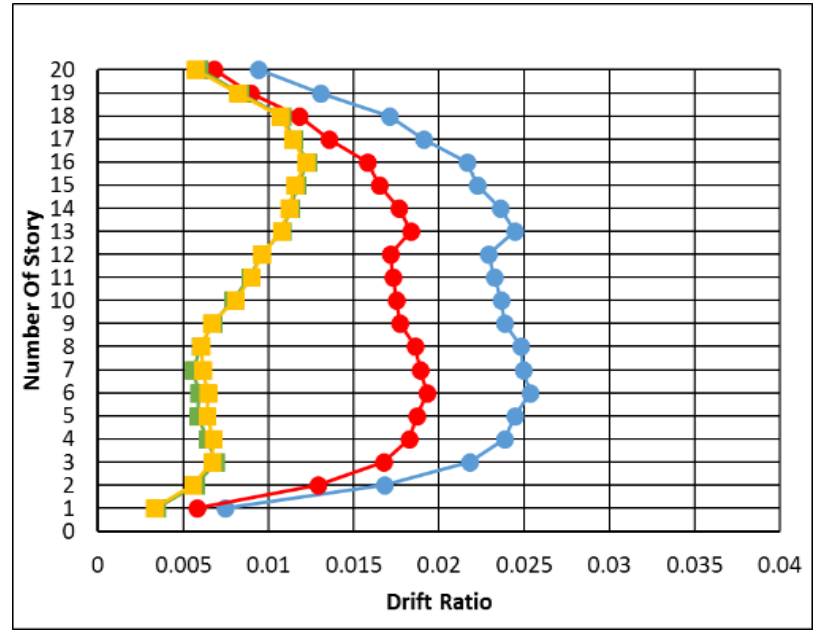

Soil Type IV

Figure 8. Drift ratio of stories of the 20 -story frame on soils type II, III, and IV under the Imperial Valley ground motion - w/o TMD-Fix - w/TMD-Fix $\quad-$ w/o TMD-NLSSI - w/ TMD-NLSSI

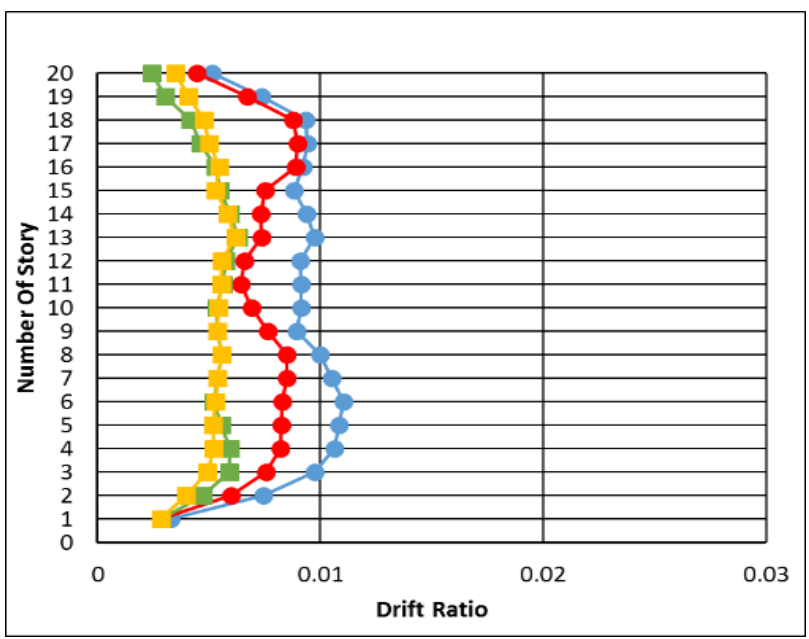

Soil Type II

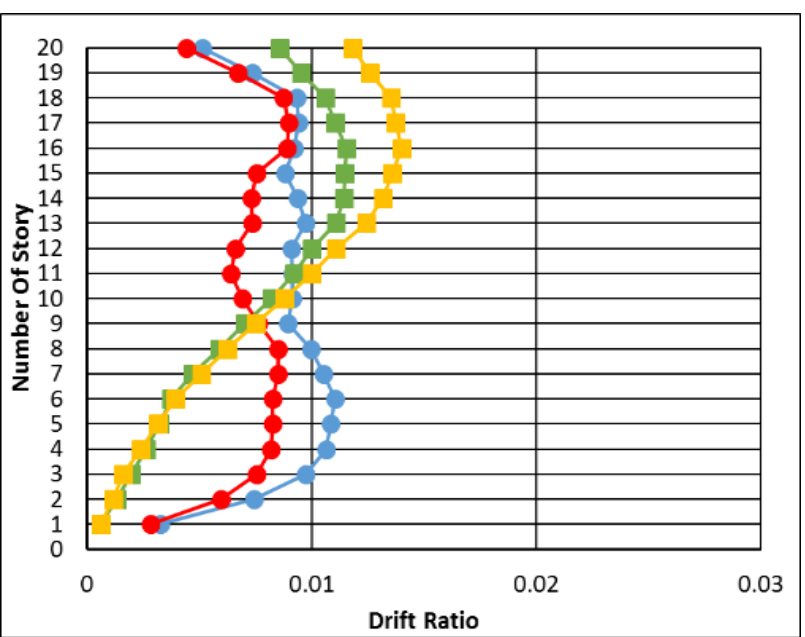

Soil Type III 


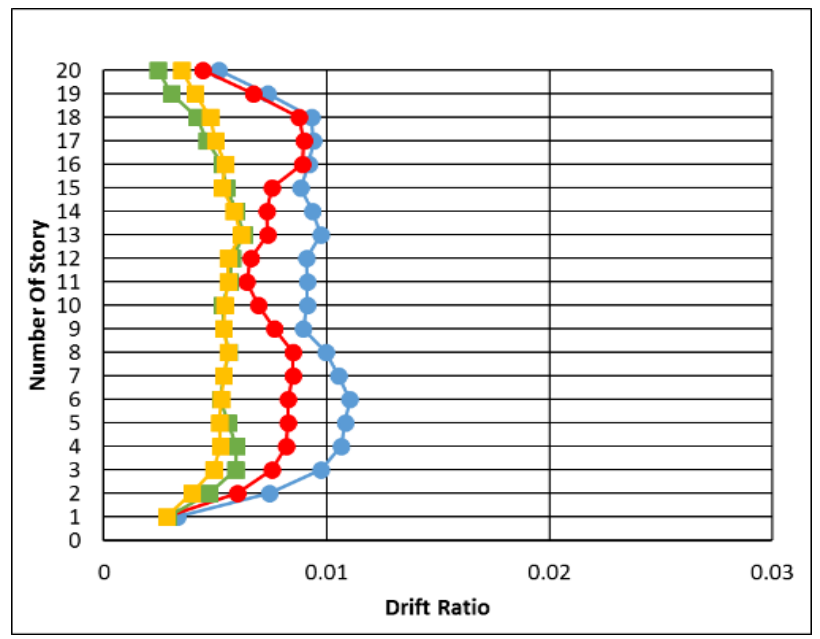

Soil Type IV

Figure 9. Drift ratio of stories of the 20-story frame on soils type II, III, and IV under the Kobe ground motion

In the 10-story frame on type III or moderate soil, under the Imperial Valley ground motion, the efficiency of the mass damper increased by $8.23 \%$ relative to the rigid base state. However, in the type II or hard soil in this frame, the mass damper produced an inverse effect on the structure, and increased the drift ratio by $3.07 \%$ relative to the case without a mass damper.

In the 10 and 15-story frames on all three soil types, under the Kobe ground motion, the nonlinear interaction has increased the efficiency of the mass damper. In the 20-story frame on soil type II, under the Kobe ground motion, the mass damper efficiency has increased and the drift ratio has been reduced by $26.98 \%$, however the inverse effect and a decrease in the efficiency of the damper were observed in soils type III and type IV, respectively. In soils type II and III, respectively $15.29 \%$ and $9.94 \%$ increase were seen in the drift ratio, i.e., the inverse damping effect. The efficiency of the mass damper in the 15-story frame under the Irpinia ground motion has increased compared to the rigid base with respect to non-linear interaction in all three soil types. However, in the same ground motion in the 10-story frame, considering the nonlinear interaction in all three types of soil, the efficiency of the mass damper was reduced relative to the rigid base and had an inverse effect on the structure, increasing the drift ratio of the structure.

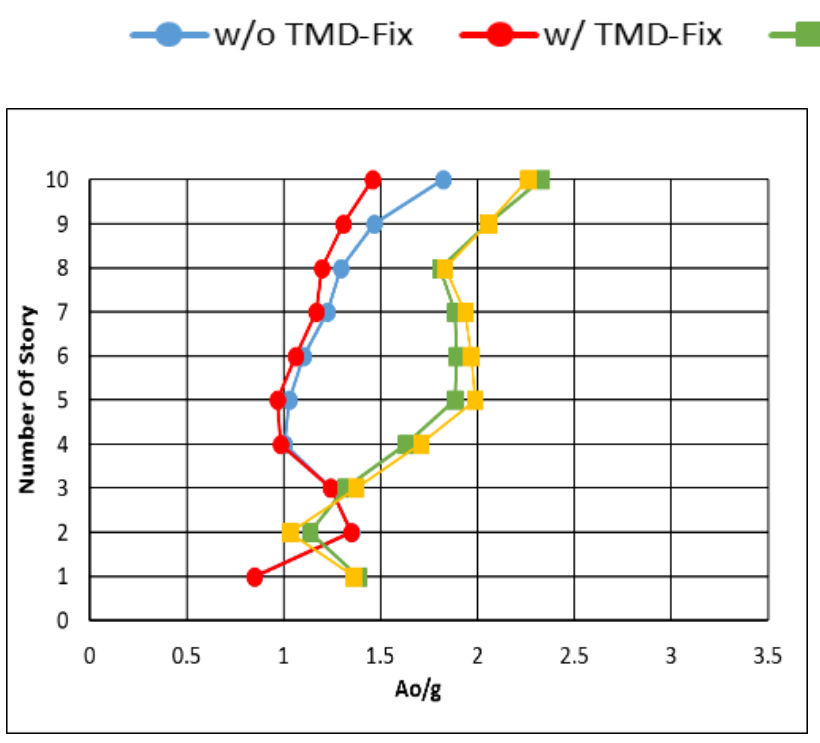

Soil Type II

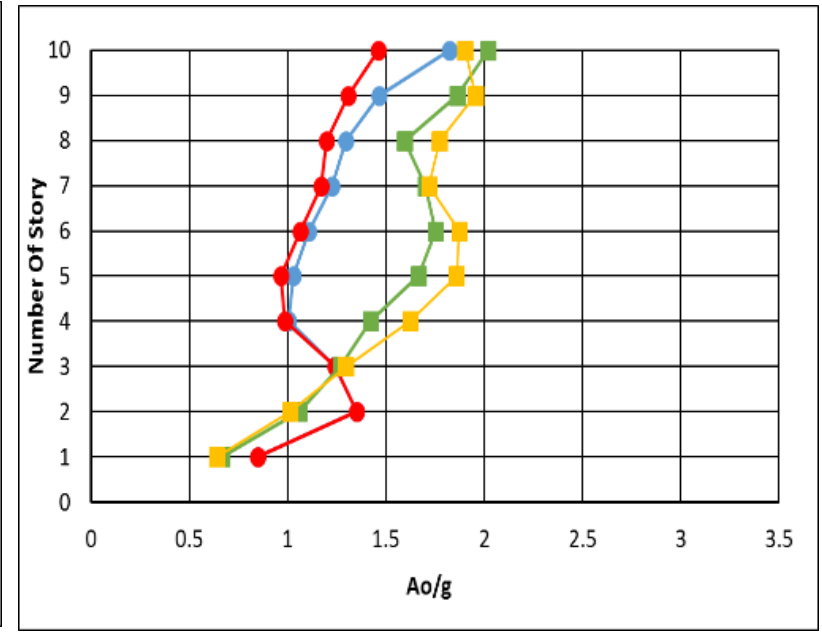

Soil Type III 


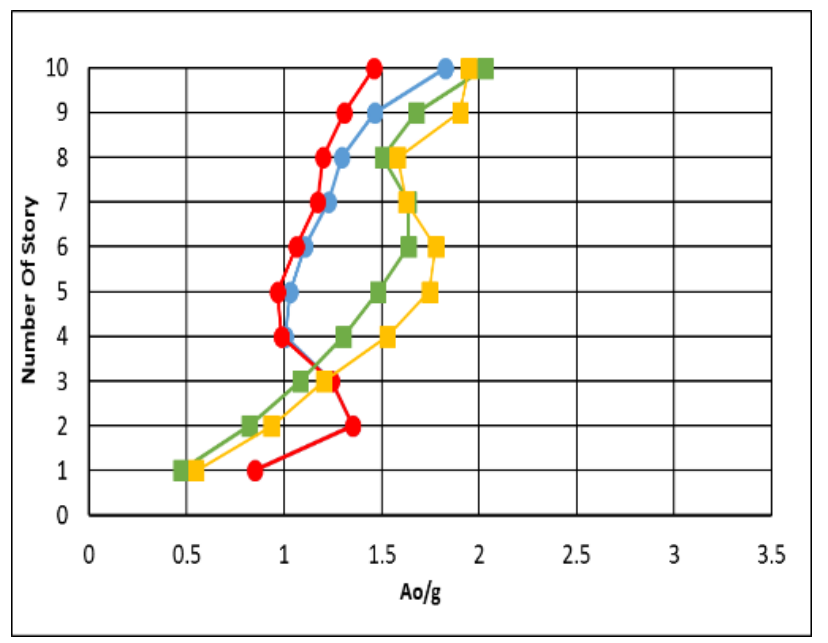

Soil Type IV

Figure 10. Absolute acceleration of stories of the 10-story frame on soils type II, III, and IV under the Imperial Valley ground motion

$\multimap$ w/o TMD-Fix $\multimap$ w/ TMD-Fix - w/o TMD-NLSSI - w/ TMD-NLSSI

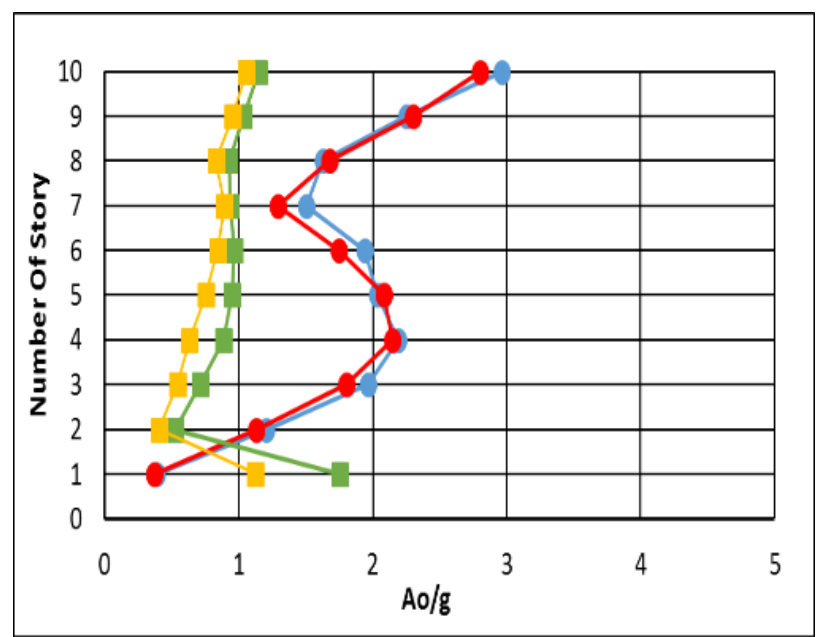

Soil Type II

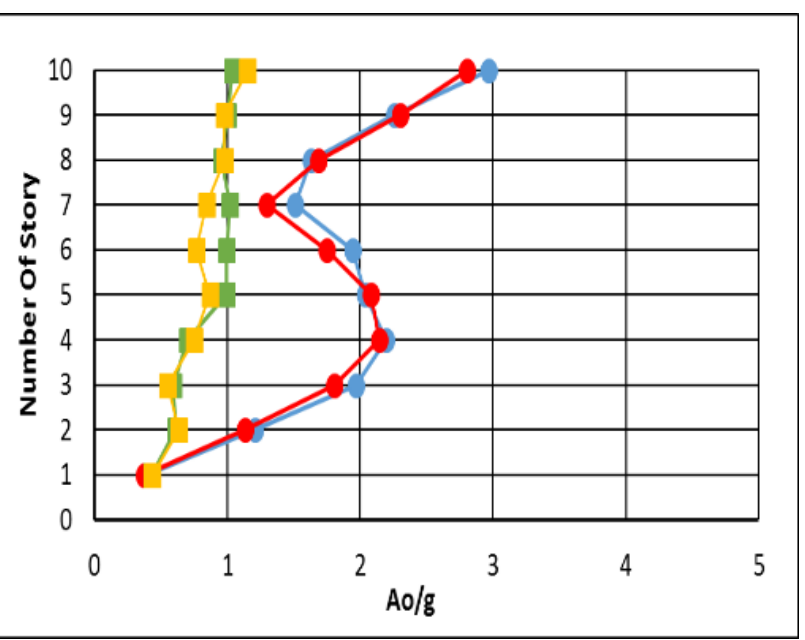

Soil Type III

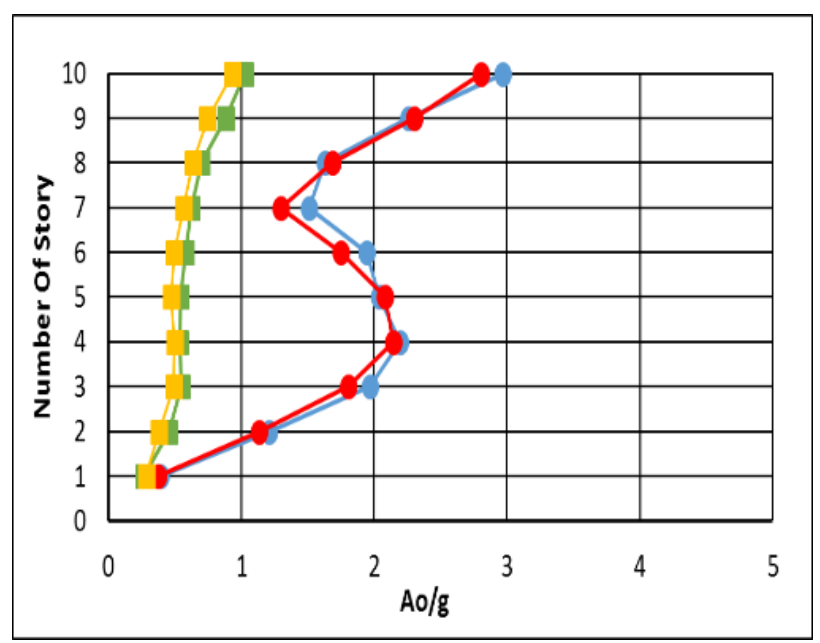

Soil Type IV

Figure 11. Absolute acceleration of stories of the 10-story frame on soils type II, III, and IV under the Kobe ground motion 


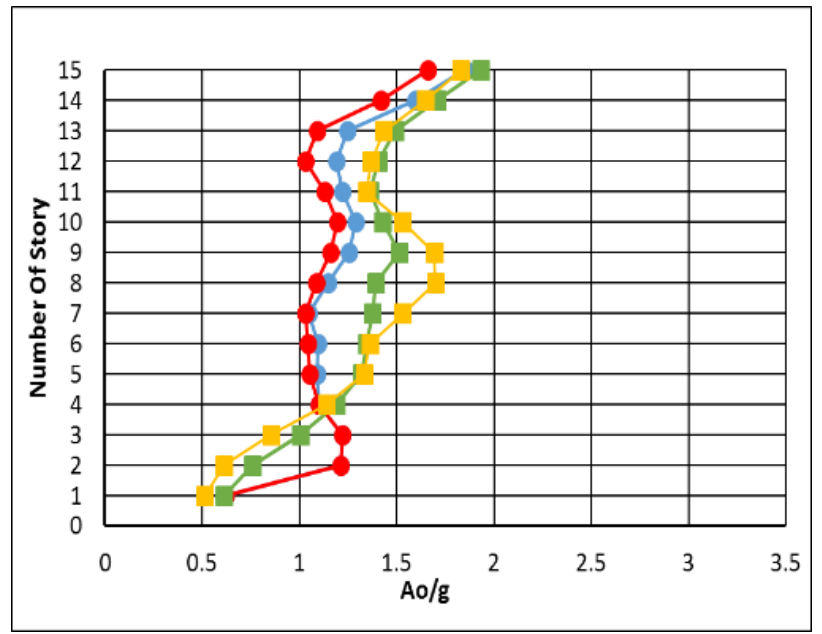

Soil Type II

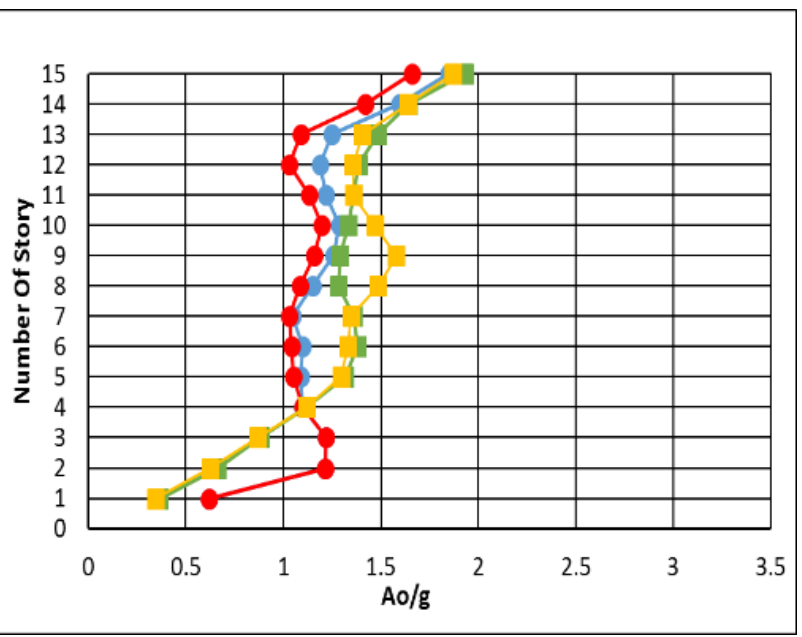

Soil Type III

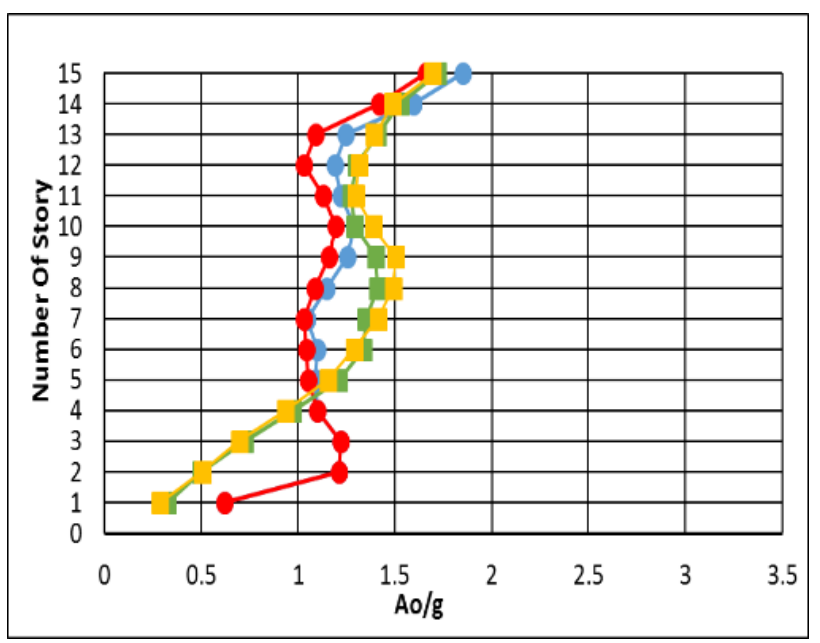

Soil Type IV

Figure 12. Absolute acceleration of stories of the 15-story frame on soils type II, III, and IV under the Imperial Valley ground motion

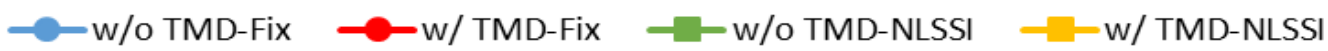

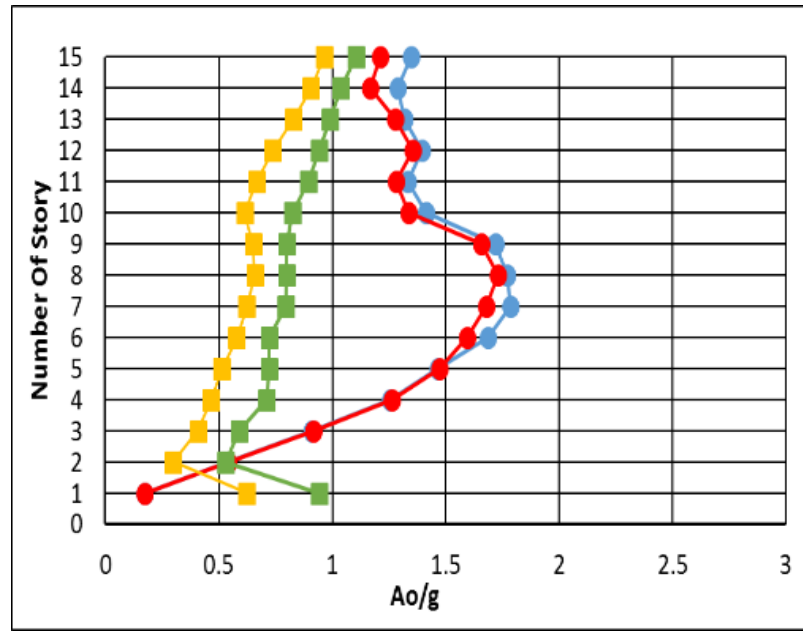

Soil Type II

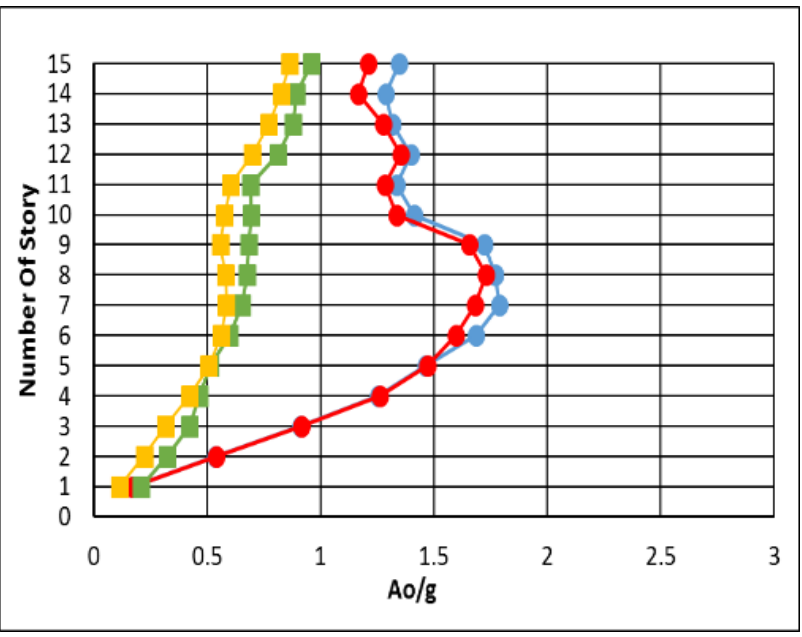

Soil Type III 


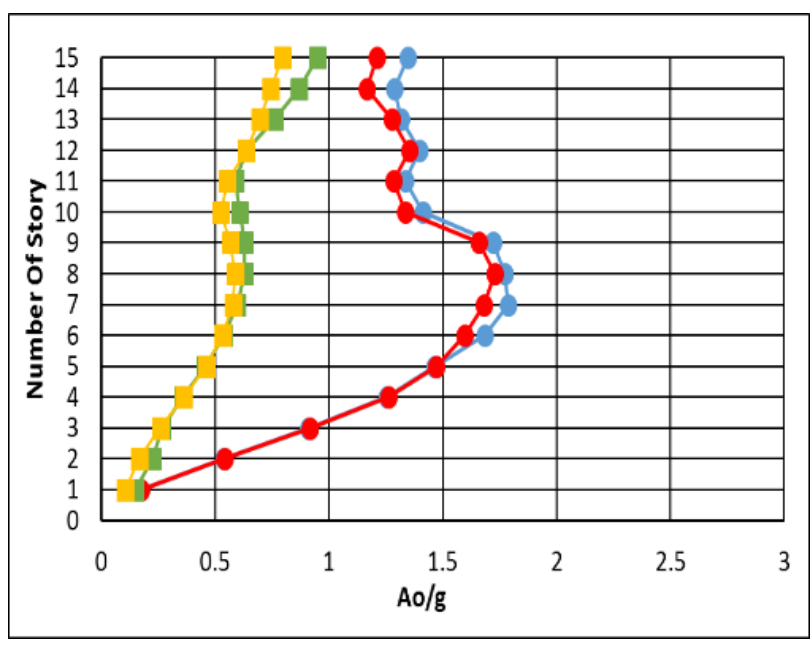

Soil Type IV

Figure 13. Absolute acceleration of stories of the 15-story frame on soils type II, III, and IV under the Kobe ground motion $-w / o$ TMD-Fix $-w /$ TMD-Fix - w/o TMD-NLSSI - w/ TMD-NLSSI

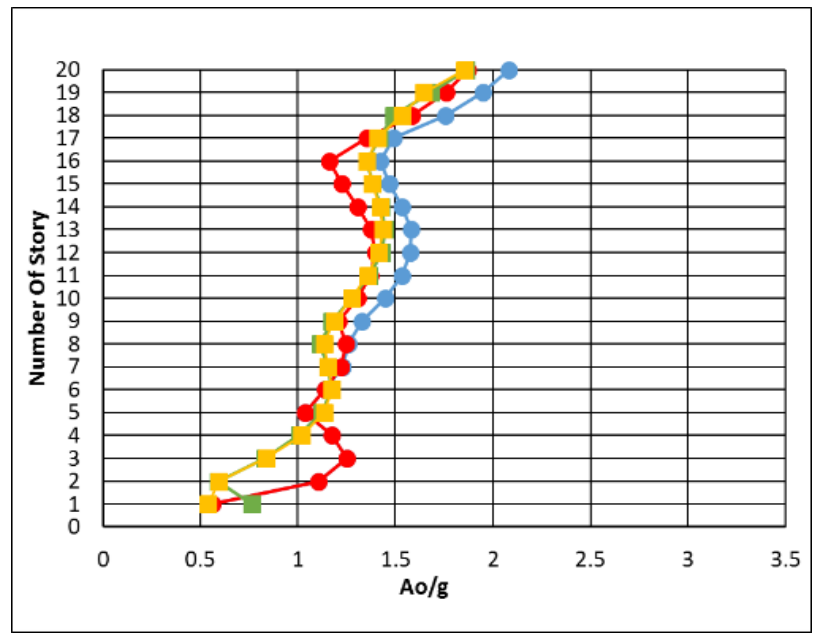

Soil Type II

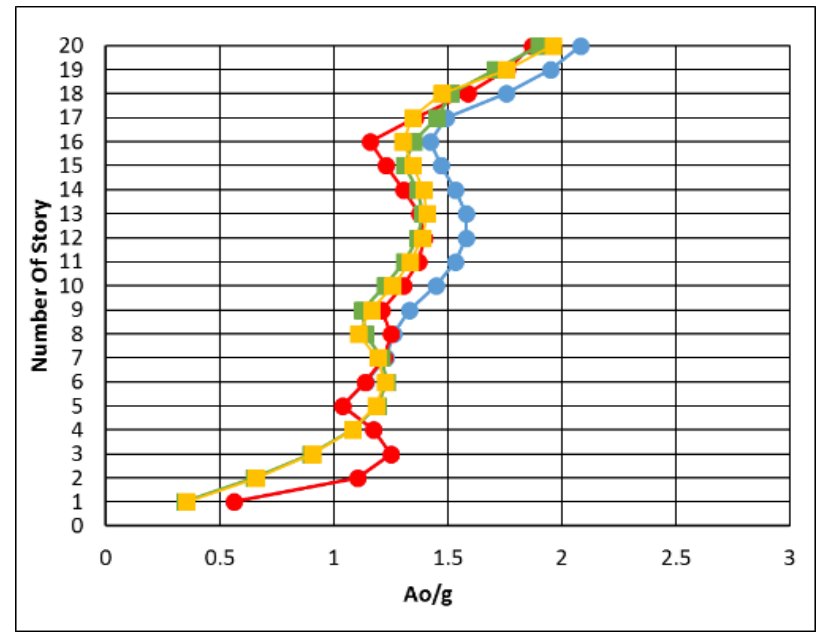

Soil Type III

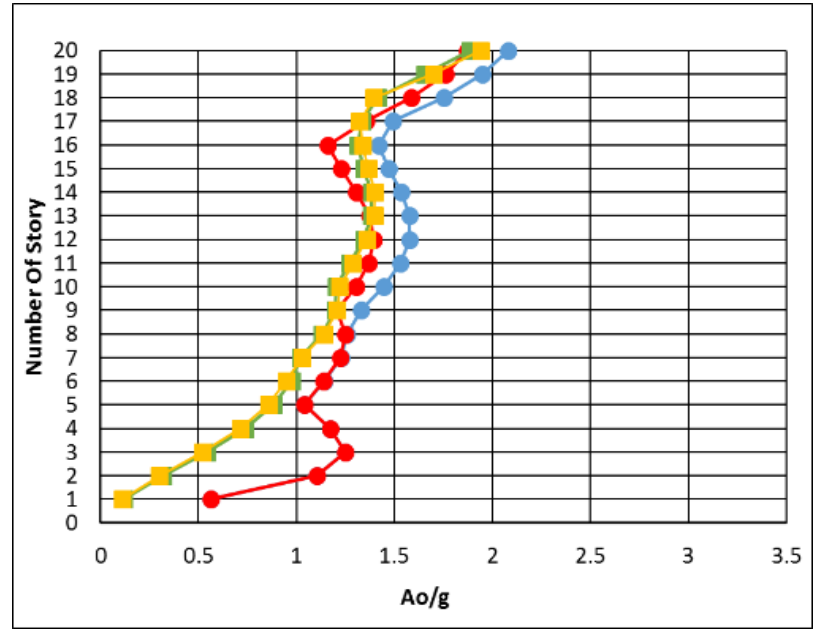

Soil Type IV

Figure 14. Absolute acceleration of stories of the 20-story frame on soils type II, III, and IV under the Imperial Valley ground motion 


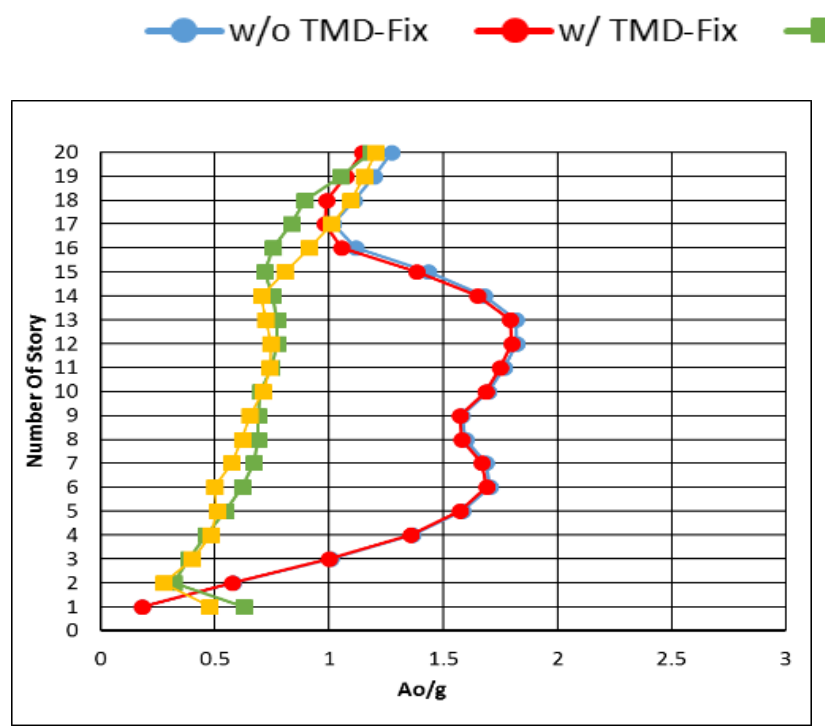

Soil Type II w/o TMD-NLSSI $-\mathrm{w} / \mathrm{TMD}-\mathrm{NLSSI}$

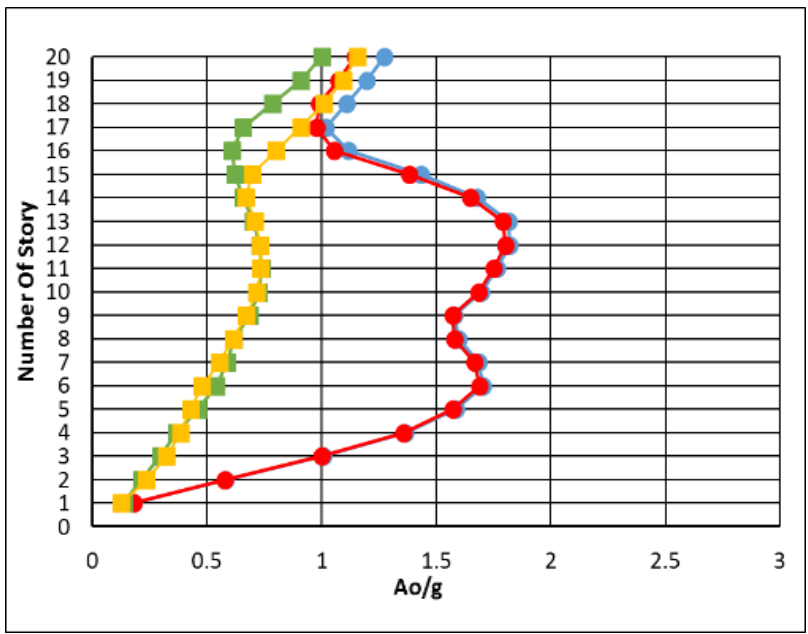

Soil Type III

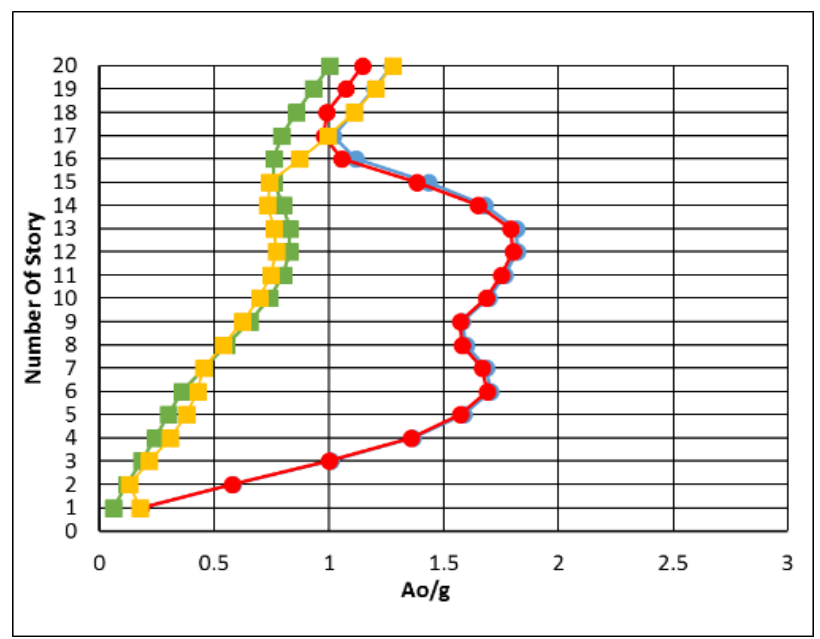

Soil Type IV

Figure 15. Absolute acceleration of stories of the 20 -story frame on soils type II, III, and IV under the Kobe ground motion

In the acceleration graphs, it can be seen that in a rigid base case, the mass damper shows its efficiency in acceleration control, on almost all stories in the 10-story frame, from the middle stories to the upper ones in the 15-story frame, and almost on the upper stories in the 20 -story frame, respectively. According to the graphs, in the Imperial Valley earthquake, the foundation uplift has a relative however not significant decrease in the absolute acceleration of the 20story frame floors before control of the structure, however in the 10 and 15-story frames, it has even increased the absolute acceleration relative to the rigid base case.

Nevertheless, in the Kobe earthquake before control of the structure by the mass damper, the nonlinear interaction causes a significant decrease in the absolute acceleration of the stories in all three structures. In the case of the 10 and 20-story frames, considering a nonlinear interaction, the mass damper has an inverse effect on the structure in controlling the acceleration of stories, and increases the response [14, 15]. 
- w/o TMD-Fix

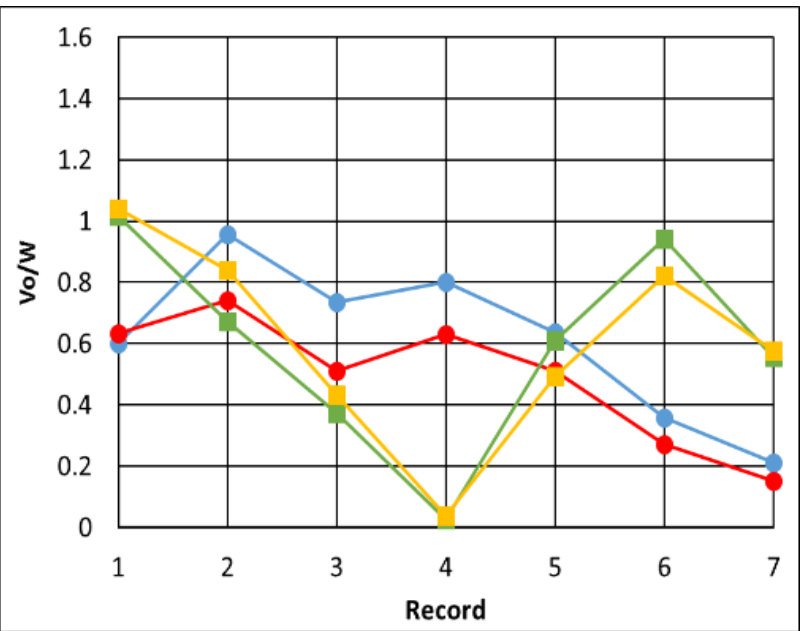

Soil Type II w/o TMD-NLSSI $-\mathrm{w} /$ TMD-NLSSI

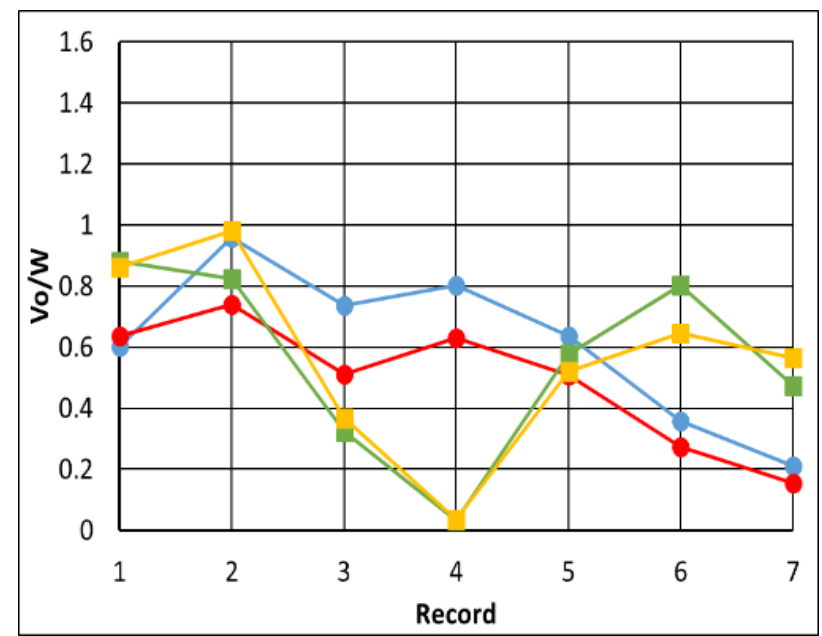

Soil Type III

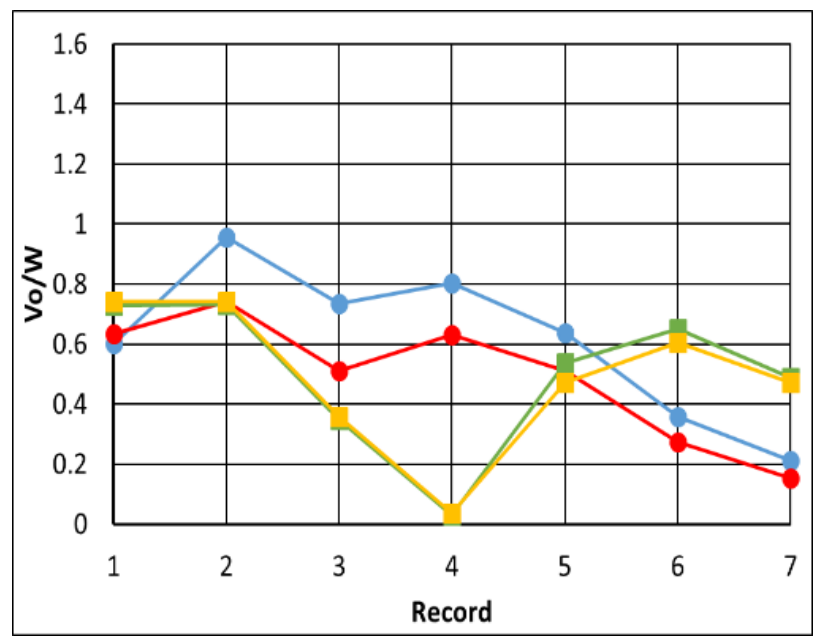

Soil Type IV

Figure 16. Base shear of the 10-story frame on soils type II, III, and IV

- w/o TMD-Fix $\quad-$ w/ TMD-Fix w/o TMD-NLSSI -w/ TMD-NLSSI

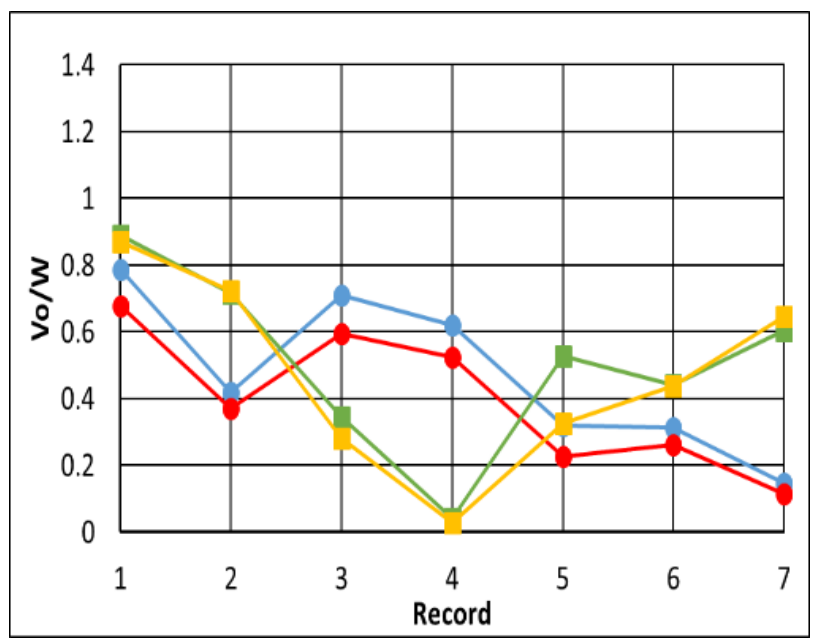

Soil Type II

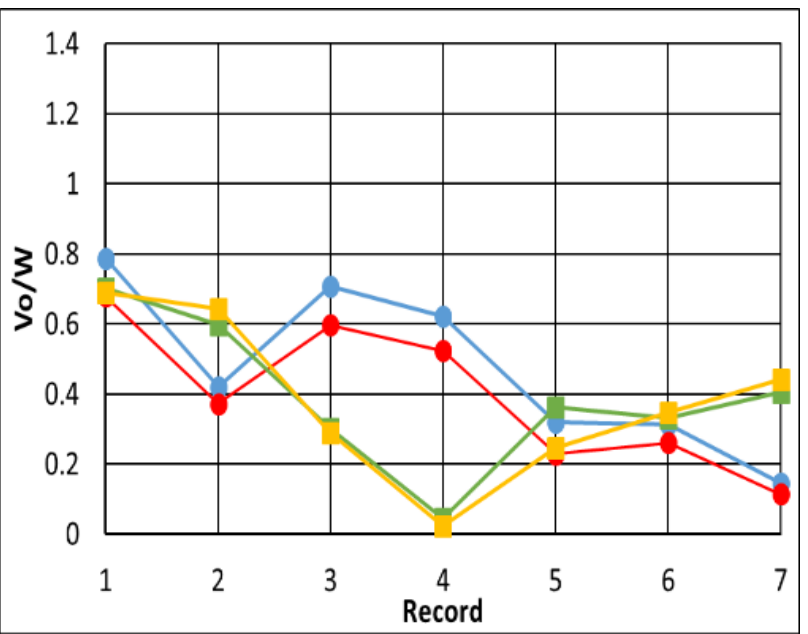

Soil Type III 


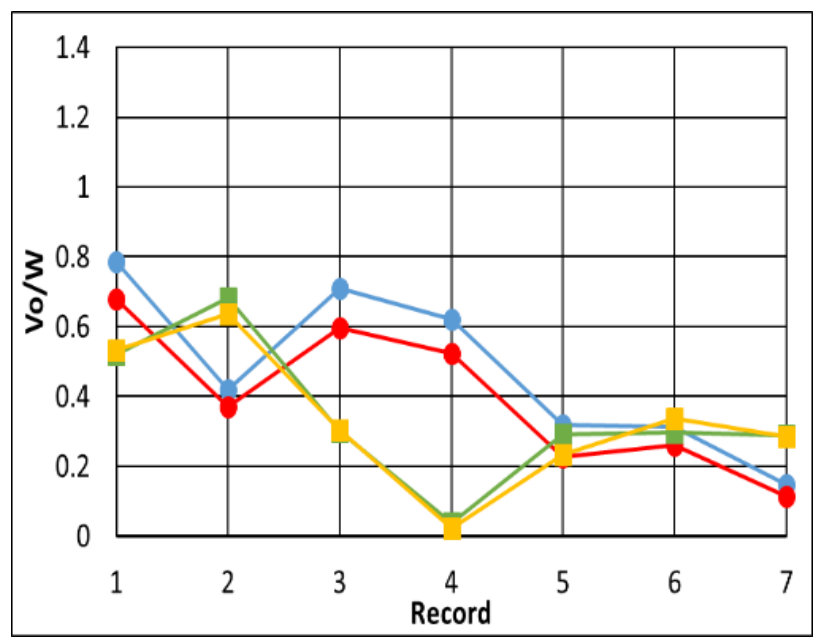

Soil Type IV

Figure 17. Base shear of the 15-story frame on soils type II, III, and IV

- w/o TMD-Fix - w/TMD-Fix - w/o TMD-NLSSI - w/ TMD-NLSSI

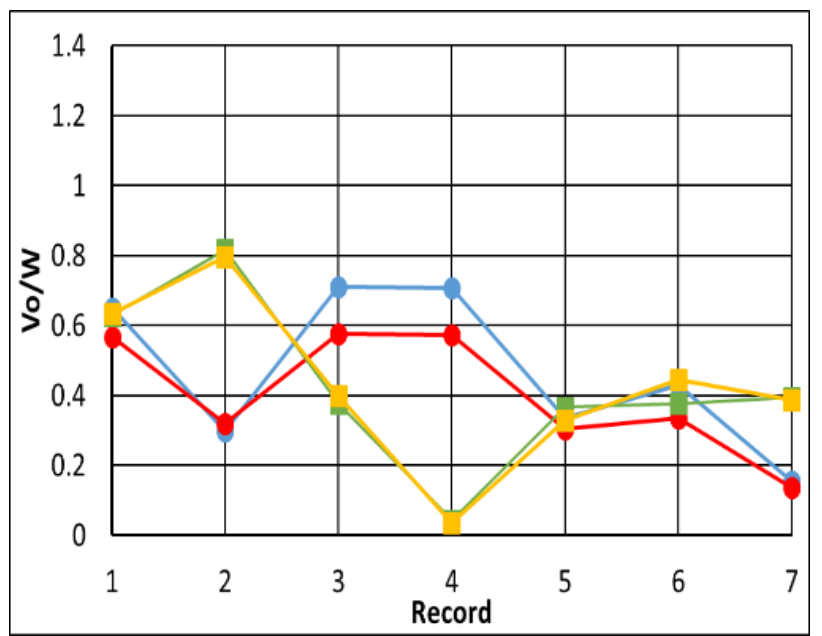

Soil Type II

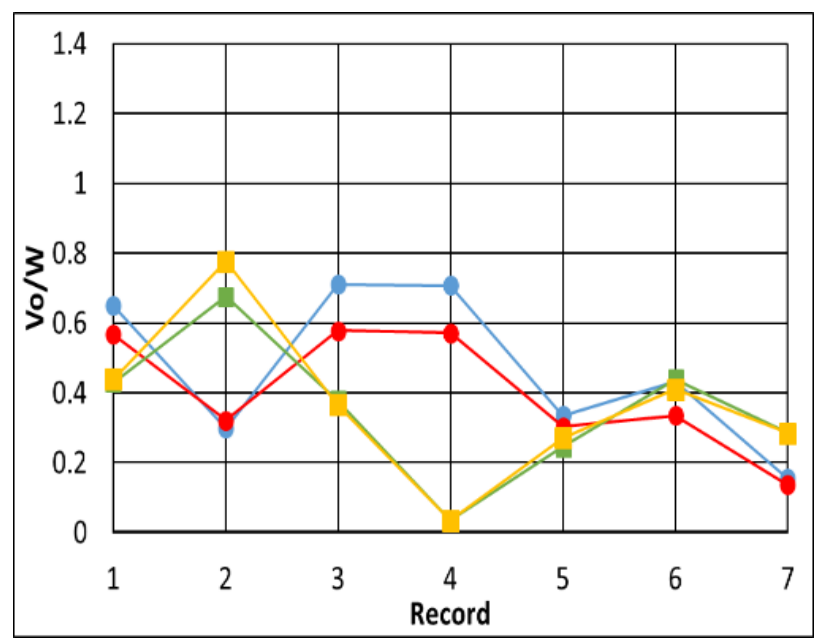

Soil Type III

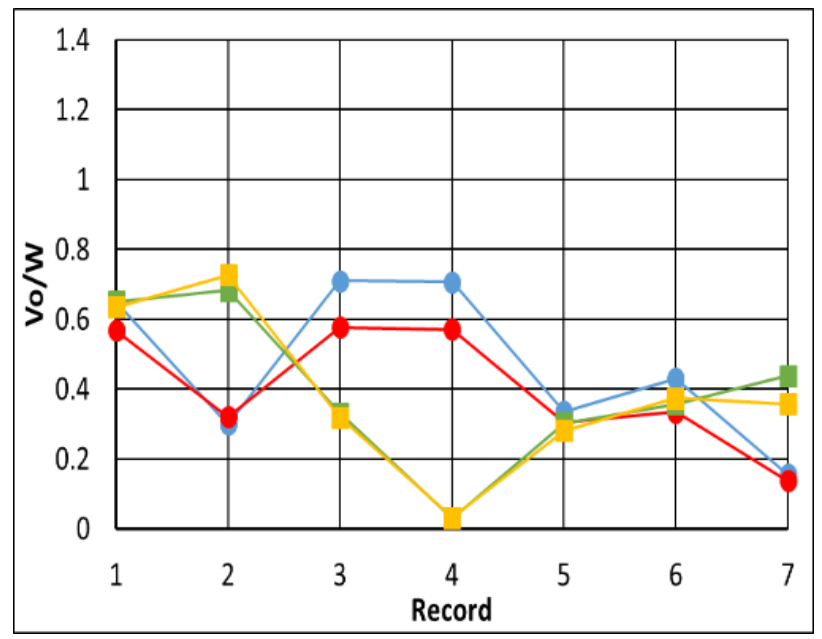

Soil Type IV

Figure 18. Base shear of the 20-story frame on soils type II, III, and IV 
Regarding the base shear peak graphs, it can be seen that in any of the three frames, before controlling the structure, the nonlinear interaction has decreased the base shear in some of the ground motions and increased in some cases. This is the same in all three soil types in the 10-story frame. However, it is different in the 15 and 20-story frames varying the type of soil and the earthquake hazard level. The mass damper in the 15-story frame has been shown to be effective in all ground motions, and in none of them has had a negative effect on the base shear control. The mass damper in the 20-story frame had some negative effect only on the base shear control in the Hector ground motion and it was effective in the rest of the ground motions. It can be observed that, considering the nonlinear interaction case, the efficiency of the mass damper in controlling the base shear decreases drastically in all three frameworks and in some cases, even increases the base shear. This is true for all the ground motions.

The greatest increase in the efficiency of the mass damper in controlling the drift ratio due to nonlinear interaction, is $47.43 \%$ reduction of the maximum drift ratio in the 15 -story frame on the type IV or soft soil under the Irpinia nearfield ground motion. It should be noted that the mass damper in the above mentioned frame with the same conditions but with a rigid base, had $14.06 \%$ efficiency in reducing the drift ratio. The largest inverse effect of the mass damper on drift ratio due to the nonlinear interaction, is the $25.56 \%$ increase in the maximum drift ratio in the 10 -story frame on the type II or hard soil under the Hector ground motion. The mass damper in the frame mentioned with the same conditions, however with a rigid base, had a $23.76 \%$ efficiency in reducing the drift ratio.

\section{Conclusions}

- Nonlinear interaction drastically reduces the efficiency of the mass damper in reducing the base shear, or causes an inverse damping effect on the structure, which is more perceptible in soft soil.

- In a shorter structure, the softer soil improves the efficiency of the mass damper in controlling the drift ratio. However, with the increase in the height of the structure, the efficiency of the mass damper further decreases with softening the soil.

- Nonlinear interaction in most ground motions reduces the efficiency of the mass damper and in some cases even increases the response, i.e., the inverse effect of the mass damper on the structure. Moreover, in some cases, it increases the efficiency of the mass damper in some ground motions.

- The efficiency of the mass damper decreases due to nonlinear interaction, in addition, the foundation uplift decreases with increasing the structure stories.

- The mass damper indicates a slight efficiency in the control of the absolute acceleration of the stories, moreover, the nonlinear interaction and the foundation uplift result in a further reduction in its efficiency, especially in soft soils.

- Nonlinear interaction significantly increases the absolute acceleration of the ceiling of the ground floor, which is larger in the short frame.

- The nonlinear interaction sharply reduced the efficiency of the mass damper in the control of the base shear in all three frames, and in some cases even increased the base shear. This is not true for all ground motions.

\section{References}

[1] Farid, P., 2002. "Effects of Interaction Phenomenon on Steel Structures". International Institute of Seismology and Earthquake Engineering, Master's thesis.

[2] Rahimian, M. B., Kamrani Moghadam, A. K., Gorbani Tanha. "Seismic Control of Structures Using a Tuned Mass Damper” First international Conference on Seismic Retrofitting, 2007.

[3] Mirhosseini. S. M. Farhad Behnamfar. "Effect of Soil and Structure Interaction on Nonlinear Dynamic Response of Structures". 7th International Conference on Seismology and Earthquake Engineering, 2015.

[4] Frahm, H., 1909. "Device for Damping Vibrations of Bodies”, US patent \#989958.

[5] Weber, Felix, Glauco Feltrin, and Olaf Huth. "Guidelines for structural control." Structural Engineering Research Laboratory, Swiss Federal Laboratories for Material Testing and Research, Dubendorf, Switzerland (2006).

[6] Ormondroyd, J. "The theory of the dynamic vibration absorber." Trans., ASME, Applied Mechanics 50 (1928): 9-22.

[7] Den Hartog, Jacob Pieter. Mechanical vibrations. Courier Corporation, York, McGraw-Hill, 1985.

[8] Xu, Chaojin, and C.C. Spyrakos. "Seismic Analysis of Towers Including Foundation Uplift." Engineering Structures 18, no. 4 (April 1996): 271-278. doi:10.1016/0141-0296(95)00059-3.

[9] Gazetas, George, and Marios Apostolou. "Nonlinear soil-structure interaction: foundation uplifting and soil yielding." In Proceedings Third UJNR Workshop on Soil-Structure Interaction, pp. 29-30. 2004.

[10] Zhou, F., M. Mori, and N. Fukuwa. "A New Uplift Foundation Analysis Model to Simulate Dynamic Nonlinear Soil-StructureInteraction." In Proceedings of the 15th world conference on earthquake engineering. 2012. 
[11] Wang, Jer-Fu, and Chi-Chang Lin. "Seismic Performance of Multiple Tuned Mass Dampers for Soil-irregular Building Interaction Systems." International Journal of Solids and Structures 42, no. 20 (October 2005): 5536-5554. doi:10.1016/j.ijsolstr.2005.02.042.

[12] Tahghighi. H. and M. Rabiee. 2017. "Influence of Foundation Flexibility on the Seismic Response of Low-To-Mid-Rise Moment Resisting Frame Buildings”. Civil Engineering Department, University of Kashan, Kashan, 87317-51167, Iran.

[13] Gajan, Sivapalan, Prishati Raychowdhury, Tara C. Hutchinson, Bruce L. Kutter, and Jonathan P. Stewart. "Application and Validation of Practical Tools for Nonlinear Soil-Foundation Interaction Analysis." Earthquake Spectra 26, no. 1 (February 2010): 111-129. doi:10.1193/1.3263242.

[14] Harden, Chad W., and Tara C. Hutchinson. "Beam-on-Nonlinear-Winkler-Foundation Modeling of Shallow, RockingDominated Footings.” Earthquake Spectra 25, no. 2 (May 2009): 277-300. doi:10.1193/1.3110482.

[15] Harden, Chad William. Numerical modeling of the nonlinear cyclic response of shallow foundations. Pacific Earthquake Engineering Research Center, 2005.

[16] Applied Technology Council. Quantification of building seismic performance factors. US Department of Homeland Security, FEMA, 2009. 